\title{
DÜBLIN
}

Technological University Dublin

ARROW@TU Dublin

\section{Diagnosis of Advanced Skin Cancer Using Infrared Spectral Histopathology}

\author{
Cassio A. Lima \\ University of Sao Paulo, Brazil \\ Luciana Correa \\ University of Sao Paulo, Brazil \\ Hugh Byrne \\ Technological University Dublin, hugh.byrne@tudublin.ie
}

See next page for additional authors

Follow this and additional works at: https://arrow.tudublin.ie/radcon

Part of the Medical Sciences Commons

\section{Recommended Citation}

Cassio, A.L. et al. (2018) Diagnosis of Advanced Skin Cancer Using Infrared Spectral Histopathology, Latin America Optics and Photonics Conference 2018, Lima Peru, 12-15 November 2018. doi:10.1364/ LAOP.2018.Tu3C.3

This Conference Paper is brought to you for free and open access by the Radiation and Environmental Science Centre at ARROW@TU Dublin. It has been accepted for inclusion in Conference papers by an authorized administrator of ARROW@TU Dublin. For more information, please contact arrow.admin@tudublin.ie, aisling.coyne@tudublin.ie,gerard.connolly@tudublin.ie.

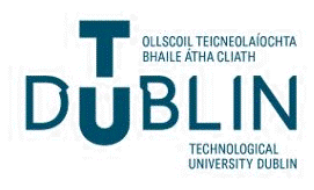




\section{Authors}

Cassio A. Lima, Luciana Correa, Hugh Byrne, and Denise M. Zezell 


\title{
Diagnosis of advanced skin cancer using Infrared spectral histopathology
}

\author{
Cassio A. Lima ${ }^{1}$, Luciana Correa ${ }^{2}$, Hugh J. Byrne ${ }^{3}$, Denise M. Zezell ${ }^{1}$ \\ ${ }^{I}$ Instituto de Pesquisas Energeticas e Nucleares, University of Sao Paulo, Sao Paulo, 05508-000, Brazil \\ ${ }^{2}$ Faculdade de Odontologia, University of Sao Paulo, Sao Paulo, 05508-000, Brazil \\ ${ }^{3}$ FOCAS Research Institute, Dublin Institute of Technology, Dublin, Dublin 8, Ireland \\ cassiolima@usp.br
}

Abstract: In this study, we investigated the feasibility of Infrared Spectral Histopathology to diagnose invasive squamous cell carcinoma using hematoxylin and eosin stained tissue placed on conventional glass slides, as used in the pathologist workflow. ㅇ 2018 The Author(s)

OCIS codes: (170.0170) Medical optics and biotechnology; (170.6510) Spectroscopy, tissue diagnostics

\section{Introduction}

The potential of FTIR spectroscopy for biomedical applications has been well demonstrated over the past decades through many proof-of-concept studies [1-3]. However, translation into clinical practice has been hindered mainly due to the expensive and fragile infrared substrates used to perform the measurements. In light of this, the present study aims to investigate the feasibility of Infrared Spectral Histopathology (SHP) using hematoxylin and eosin standard (H\&E) stained histopathology glass slides to discriminate healthy skin from invasive squamous cell carcinoma (iSCC).

\section{Methodology}

\section{Sample preparation}

Invasive squamous cell carcinoma was induced on the back of Swiss mice using a chemical carcinogenesis protocol $[4,5]$. Tissue specimens were collected from healthy and diseased mice, formalin-fixed and paraffinprocessed (FFPP). Sections of $5 \mu \mathrm{m}$ thickness were placed on conventional glass slides and submitted to H\&E staining.

\section{FTIR microspectroscopy}

FTIR hyperspectral images were acquired in transmission mode over the high wavenumber spectral region (3000-3800 $\left.\mathrm{cm}^{-1}\right)$ with a pixel size of $6.25 \times 6.25 \mu \mathrm{m}$ at a spectral resolution of $4 \mathrm{~cm}^{-1}$. Spectral data were vector normalized and the second derivative was calculated in order to reduce baseline offset and assess the overlapping sub-bands. Savitzky-Golay filter was applied for signal-smoothing using a polynomial of second order in an eleven points window. Principal Component Analysis (PCA) was performed on second derivatives and the first two principal components were used as input data for linear discriminant analysis (LDA) in a binary classification test. The groups were pairwise compared and the method was validated by leave-one-sample-out cross-validation.

\section{Results and Discussion}

Figure 1.A and B show the averaged FTIR spectra and their second derivatives collected from healthy and cutaneous iSCC. The bands peaking at 3282 and $3334 \mathrm{~cm}^{-1}$ are associated to hydroxyl (OH) stretching of water and amide A [6]. Figure 1.D show the score plot of the two main principal components obtained for invasive SCC spectra pairwise compared to healthy skin. Satisfactory data discrimination was achieved along the first principal component, in which most scores from diseased tissue are grouped on negative values of PC-1 axis and scores from healthy skin lie in the positive values. The information retained by the loading plot (Figure 1.C) indicate the variables responsible by the different groupings along PC-1 axis in the score plot. Considering that PCA was applied on second derivatives, positive scores are associated with negative loadings and negative scores relate to positive loadings.

Negative loading was evidenced for the amide A band $\left(3334 \mathrm{~cm}^{-1}\right)$, indicating a decrease of this cellular component in the diseased tissue. This band was not even observed in the averaged spectrum of the second derivative from iSCC, suggesting a dramatically reduction of this component with the disease progress. The band related to hydroxyl stretching of water presented a positive loading, which indicates an increase of water content in the mice submitted to chemical carcinogenesis. 

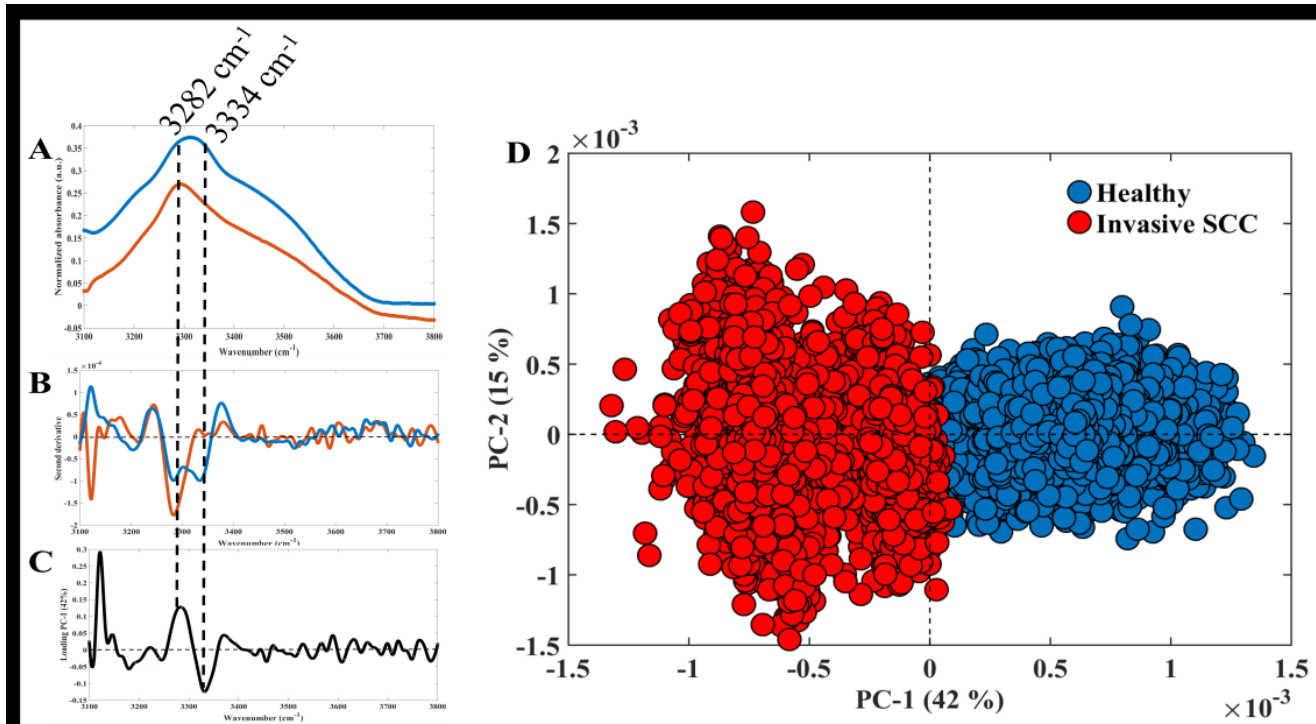

Fig. 1: High wavenumber region of averaged FTIR spectra (A) and their second derivatives (B), in which blue line represents healthy tissue and red line depicts iSCC. Figure D shows the PCA score plots using the first two principal components and $\mathrm{C}$ represents the loading plot associated to $\mathrm{PC}-1$.

Satisfactory data discrimination were achieved using the first two principal components as input data for PC-LDA, resulting in sensitivity, specificity and accuracy values over 90\%. Thus, although the "fingerprint" region of MID infrared (900-1800 $\mathrm{cm}^{-1}$ ), which is widely used as is not accessible while using conventional glass slides as substrates, we demonstrate that the information contained in the high wavenumber range is sufficient to discriminate normal and malignant tissue using H\&E stained samples as received from the pathologist.

\section{Conclusions}

In this study, we demonstrate that the information contained in the high wavenumber range of FTIR spectra is sufficient to discriminate healthy and invasive squamous cell carcinoma tissue using H\&E stained samples on a glass substrate as received from the pathologist.

\section{References}

1. M. J. Baker, H. J. Byrne, J. Chalmers, P. Gardner, R. Goodacre, A. Henderson, S. G. Kazarian, F. L. Martin, J. Moger, N. Stone, and J. Sule-Suso, "Clinical applications of infrared and Raman spectroscopy: state of play and future challenges," Analyst 143, 1735-1757 (2018).

2. C. A. Lima, V. P. Goulart, L. Correa, and D. M. Zezell, "Using Fourier transform infrared spectroscopy to evaluate biological effects induced by photodynamic therapy," Lasers Surg Med 48, 538-545 (2016).

3. C. A. Lima, V. P. Goulart, L. Correa, T. M. Pereira, and D. M. Zezell, "ATR-FTIR spectroscopy for the assessment of biochemical changes in skin due to cutaneous squamous cell carcinoma," Int J Mol Sci 16, 6621-6630 (2015).

4. E. L. Abel, J. M. Angel, K. Kiguchi, and J. DiGiovanni, "Multi-stage chemical carcinogenesis in mouse skin: fundamentals and applications," Nat Protoc 4, 1350-1362 (2009).

5. C. A. Lima, V. P. Goulart, E. J. Bechara, L. Correa, and D. M. Zezell, "Optimization and therapeutic effects of PDT mediated by ALA and MAL in the treatment of cutaneous malignant lesions: A comparative study," J Biophotonics 9, 1355-1361 (2016).

6. Z. Movasaghi, S. Rehman, and D. I. ur Rehman, "Fourier Transform Infrared (FTIR) Spectroscopy of Biological Tissues," Appl Spectrosc Rev 43, 134-179 (2008).

\section{Acknowledgments}

This work was supported by FAPESP CEPID 05/51689-2, CAPES (PROCAD 88881.068505/2014-01, PDSE: 88881.132771/2016-01); CNPq (INCT 465763/2014-6, PQ 309902/2017-7, PhD grant 141629/2015-0) 